\title{
Multiple Pathways: The Influence Mechanism of Greenspace Exposure on Mental Health-A Case Study of Hangzhou, China
}

\author{
Jiancheng $\mathrm{Lu}^{1}{ }^{1}$, Xiaolong Luo ${ }^{1}$, Ningning Yang ${ }^{1}{ }^{1}$ and Yang Shen ${ }^{2, *} \mathbb{( \mathbb { D }}$ \\ 1 School of Architecture and Urban Planning, Nanjing University, Hankou Road No. 22, Nanjing 210093, China; \\ ljcnju@smail.nju.edu.cn (J.L.); xluo@nju.edu.cn (X.L.); mf1936071@smail.nju.edu.cn (N.Y.) \\ 2 Center of Planning and Design, Wuxi Institute of Urban Planning and Design, Xixin Road No. 8, \\ Wuxi 214000, China \\ * Correspondence: yswxup@yeah.net
}

check for updates

Citation: Lu, J.; Luo, X.; Yang, N.; Shen, Y. Multiple Pathways: The Influence Mechanism of Greenspace Exposure on Mental Health-A Case Study of Hangzhou, China. Land 2021, 10, 339. https://doi.org/ 10.3390/land10040339

Academic Editor: Dagmar Haase

Received: 1 March 2021

Accepted: 23 March 2021

Published: 27 March 2021

Publisher's Note: MDPI stays neutral with regard to jurisdictional claims in published maps and institutional affiliations.

Copyright: (c) 2021 by the authors. Licensee MDPI, Basel, Switzerland. This article is an open access article distributed under the terms and conditions of the Creative Commons Attribution (CC BY) license (https:/ / creativecommons.org/licenses/by/ $4.0 /)$.

\begin{abstract}
Greenspace exposure (GSE) may have a positive impact on mental health. However, existing research lacks a classification analysis of the influence pathways of different GSE on mental health. Meanwhile, the research method is limited to the measurement of the green space ratio (GSR) based on remote sensing data, which ignores people's real perception of greenspace. This paper aims to further expand the measurement method of GSE, taking Hangzhou, China as an example, and to reveal the influence mechanism of different GSE modes on mental health. We obtained the personal information, mental health, physical activity, and other data of the interviewees through a questionnaire $(n=461)$. Combined with a remote sensing satellite and the Baidu Street view database, the method of image interpretation and deep learning was used to obtain the GSR, green visual ratio (GVR), and green visual exposure (GVE). The structural equation model is used to analyze the relationship between different variables. The results showed that: (1) GSE has a certain positive effect on mental health; (2) there are differences in the influence mechanism of multiple measures of GSE on mental health-the GVR and GVE measures based on the interaction perspective between human and greenspace make the influence mechanism more complicated, and produce direct and indirect influence paths; and (3) greenspace perception, sense of community, and physical activity can act as mediators, and have indirect effects. Finally, we call for expanding the measurement index and methods of GSE and integrating them into the management and control practices of urban planning to promote the healthy development of communities and even cities.
\end{abstract}

Keywords: multiple pathways; greenspace exposure; mental health; deep learning; influence mechanism; Hangzhou

\section{Introduction}

Since the last century, the rapid development of cities and industries has driven the advancement of the economy, culture, and society in developing countries. At the same time, urban air quality, natural environment, and infrastructure are facing huge challenges, leading to the emergence and aggravation of overall urban health threats, such as frequent natural disasters, epidemic outbreaks, ecological damage, and plant degradation [1]. From the perspective of China, the rapid development of cities after reform and opening up has aggravated the damage to the ecological environment, which has led to various health crises [2]. The urban living that is disconnected from greenspace results in mental fatigue and stress. This can cause many physical and mental illnesses, such as diabetes, obesity, anxiety, high blood pressure, and respiratory problems [3]. Thus, it can be seen that greenspace has an important impact on the health of cities and people [4].

There is increasing evidence showing a positive relationship between greenspace and health [5]. We use the term "greenspace" to mean various types of land functions, including developed or undeveloped green land, which is opened to the public within a town or city [6]. It can also include private gardens, community gardens, urban parks [7], and 
accessible spaces for citizens, including grassy areas [8], cemeteries [9], waterfront areas, and street trees [6]. Some scholars believe that the accessibility, coverage area, and spatial form of urban greenspace all have a positive impact on life expectancy $[10,11]$, as well as obesity rate, type 2 diabetes, stroke, and heart disease among nearby residents [12-14]. The physical function and psychological endurance of residents with a high frequency of participating in the activities of greenspace are indeed better than those with a low frequency [15]. In addition, patients who are recovering from serious illness living in the greenspace can reduce recovery time and relieve postoperative pain [11-13]. Some scholars believe that urban greenspaces, depending on their characteristics and accessibility, can be used for relaxation, fitness, entertainment, building social relationships, and spending time with colleagues, friends, and family [16]. These functions support different types of healthy activities, and thus may contribute to physical, mental, and social health [5].

As mentioned above, the interaction between people and greenspace is conducive to health, which depends on continuous exposure to it, and some scholars call this greenspace exposure (GSE) $[17,18]$. The term GSE originated from medical scholars' research on epidemics [18]. As the impact of greenspace on health becomes more and more prominent, GSE in the fields of ecology, environmental science, geography, and urban planning has received extensive attention and applications [19-21]. The research content mainly focuses on the impact of GSE on physiological diseases and mental diseases [22,23]. In 2018, Utrecht University held the NEEDS (Dynamic Urban Environmental Exposures on Depression and Suicide) conference to reveal the influence mechanism of GSE on anxiety and other mental diseases, and made a series of progresses [24].

The impact of GSE on mental health has reached a broad consensus. Some scholars believe that part of the effects are positive [25], such as relieving occupational stress, improving depression, enhancing sleep, and establishing a positive attitude [26,27]. However, existing research also has some shortcomings. For example, the measurement methods for GSE are distribution, form, area, and accessibility, while the measurement methods for human participation in greenspace are time, location, frequency, etc., which leads to research often based on a single perspective of people or greenspace, while ignoring the interaction between them. Therefore, in order to reveal the influence mechanism of GSE on mental health more accurately, we propose different GSE measurement methods based on the perspective of human/greenspace interaction, and try to answer the following questions: (1) Do different GSE measurement methods (GSR, GVR, or GVE) lead to diverging results? (2) When the measurement method of GSE considers the actual reception of people, is the influence path more complex and diversified? (3) What are the influence mechanisms?

\section{Theoretical Review and Conceptual Framework}

\subsection{Theoretical Review}

\subsubsection{GSE and Health}

Since 2010, the effects of GSE on physical, psychological, social, and environmental health have attracted many scholars' attention, and a series of results have been achieved. At the same time, the research direction also presented a new trend. First, it promotes physical health, such as enhancing physical fitness [28], improving nutrition [29], ensuring food safety [30], promoting recovery from disease [28], inhibiting cancer progression [31], reducing obesity and cervical spondylosis [32-34], and extending life span [35]. In addition, it reduces the risk of premature or underweight birth [36]. Second, it has an ameliorating effect on mental sickness, such as negativity, depression, and phobias [37]. Participating in greenspace activities can shape residents' optimism [38], sense of well-being, and pride [39], and enhance students' creativity [40]. Third, it plays an active role in promoting social equity [41,42], building social relations [43,44], ensuring community security $[45,46]$, and increasing social and economic capital [47-49]. Fourth, it improves environmental health. Greenspace has a significant effect on improving air quality [50], enriching biodiversity [51], slowing down green degradation [52], and reducing the threat of natural disasters [53]. 


\subsubsection{GSE and Mental Health}

The research methods of the impact of GSE on mental health have gone through several iterations. The earliest measurement was based on the location, duration, and frequency of individual participation in greenspace [37], or the distribution, area, and accessibility of greenspace [35]. These research methods are all based on two-dimensional indicators for analysis. In 1987, Japanese scholars put forward the concept of the green visual ratio (GVR), which refers to the proportion of greenspace observed by the human eye [54]. Subsequently, the research on the GVR was widely carried out, and rich results were obtained. For example, a high GVR can relax residents' mood and help maintain a positive attitude [55]. In addition, some scholars put forward the panoramic green visual ratio, trying to deepen the measurement method of the GVR.

Although the proposal of the GVR reflects the interaction between human and greenspace to a certain extent, it is essentially a measurement of greenspace, and does not consider the actual exposure value of greenspace received by people [56]. Based on these considerations, some scholars believe that the traditional static space research methods have great shortcomings, which leads to the urgent need to shift the research perspective to activity space, and to include GSE in the process of daily activities into the research scope, not just GSE at a fixed location [57].

\subsection{Conceptual Framework}

Based on the above literature review of GSE and mental health, we are trying to establish a new conceptual framework (Figure 1). The measurement methods of GSE are divided into three aspects: greenspace measurement, human behavior measurement, and human/greenspace interaction measurement. Among them, the greenspace measurement includes the GSR, GVR, green space area, and plant types. Personal behavior measurement includes the time, duration, frequency, and content of participating in the greenspace. The measurement of interaction between humans and greenspace refers to the information that people receive in the greenspace, that is, GSE. Some scholars believe that green visual exposure (GVE) is a type of GSE, and its measurement methods include exposure intensity and total exposure. Exposure intensity refers to the instantaneous exposure level of people in the greenspace. The total exposure refers to the sum of the exposure intensity within a certain period of time [56].

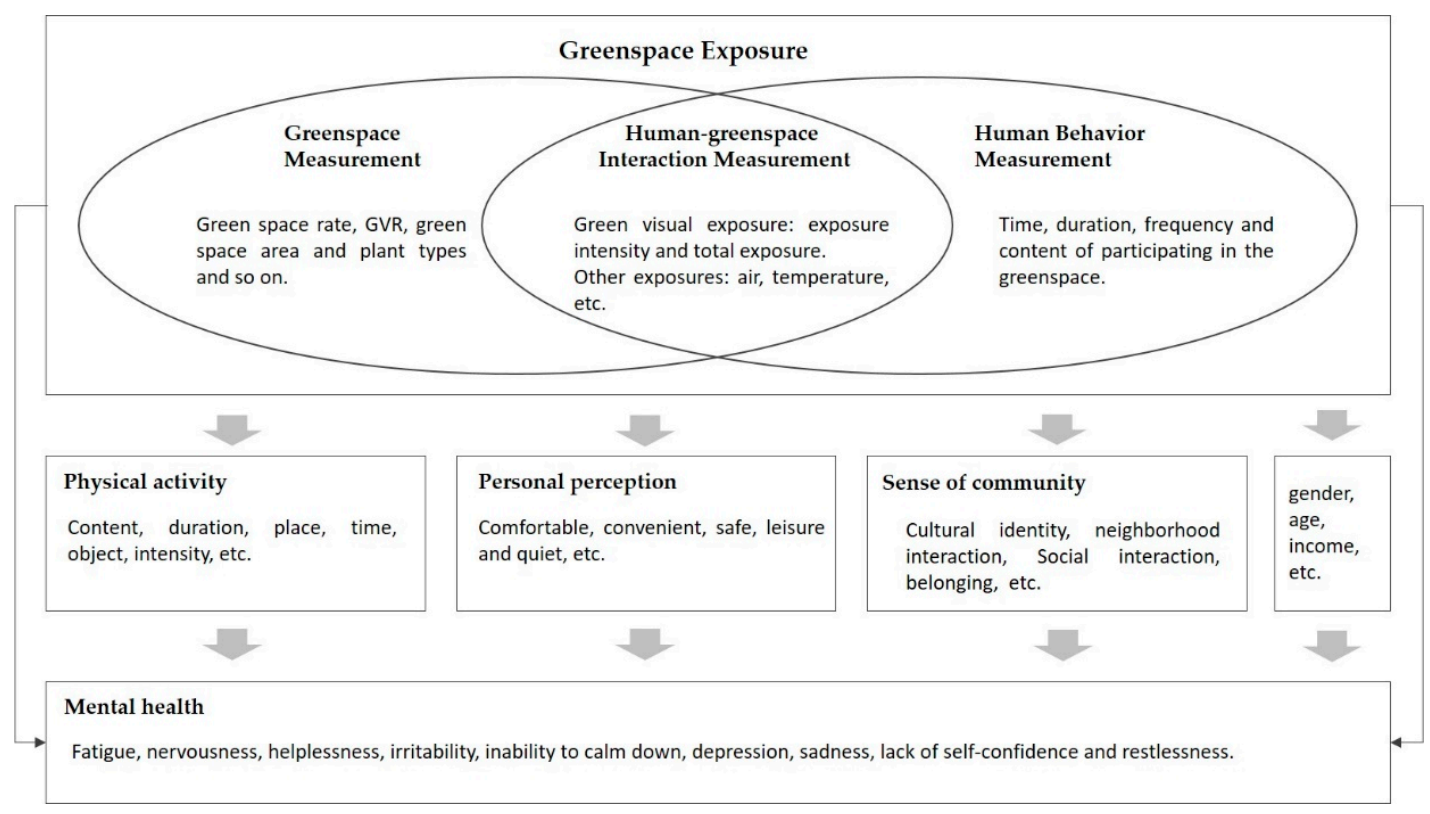

Figure 1. Conceptual framework. 
The mental health measurement method refers to the Kessler Psychological Distress Scale. Chinese scholars have verified its credibility, and proposed that it is widely applicable to the mental health assessment of the Chinese urban population [58]. The Kessler Psychological Distress Scale divides the mental test content into fatigue, nervousness, helplessness, irritability, inability to calm down, depression, sadness, lack of self-confidence, and restlessness. In addition, the impact of GSE on mental health is also indirect. Physical activity, personal perception, and sense of community in the greenspace all have an indirect impact on mental health, which is also called an intermediary factor [59]. Other factors, such as gender, age, income, road density, etc., can also be incorporated into the conceptual framework as control variables.

\section{Material and Methods}

\subsection{Study Objects}

This paper selects 13 communities in Hangzhou as the research object, which are located in the old city, the new city, and the scenic area. There are huge differences in the construction age, population structure, house price, GSR, spatial distribution, etc., which are feasible and reliable for empirical research. Data were obtained from the 13 communities in August 2020. Through consultation with community managers, we selected residents with potential psychological stress as sample objects, such as high school students, newly employed graduates, doctors, scientific research workers, financial analysts, retired elderly people with low living security, etc., all of which have obvious sources of stress (time pressure, life pressure, etc.). Constant exposure to greenspace may counteract these psychological pressures. We gave a brief introduction to the selected sample and invited them to participate in a survey of their living environment and quality of life, as well as their ethnic, cultural, economic, and political backgrounds, to ensure that the data varied enough. At the same time, in order to know the community well, they must have lived in their current community for more than a year. Those who had lived in their community for less than a year, who did not state their address, and did not clearly understand the questionnaire were excluded.

A total of 689 questionnaires were sent out to 13 communities, among which two communities did not provide enough information about physical activities, one community had incomplete mental health data, and one community had an insufficient number of questionnaires. In the end, the study eliminated four communities with poor questionnaire quality (Figure 2). A total of 461 valid questionnaires were obtained through sorting out the contents of the remaining nine communities (Table 1). The whole process of the study was consistent with the basic principles set out in the Declaration of Helsinki. All participants signed an informed consent to have their information processed and stored in accordance with China's Code of Ethics and Academic Research. No rewards were offered to those who agreed to participate, and there were no penalties for those who did not. The study design was reviewed by academic boards to ensure that there were no ethical concerns (e.g., Institutional Review Board certification).

Table 1. Socioeconomic attributes of the survey samples.

\begin{tabular}{|c|c|c|c|c|c|c|c|}
\hline Feature & Options & Percentage & Variable & Feature & Options & Percentage & Variable \\
\hline \multirow{2}{*}{ Gender } & Male & $47 \%$ & 0 & \multirow{5}{*}{$\begin{array}{c}\text { Average } \\
\text { monthly salary }\end{array}$} & $<3000 \mathrm{RMB}$ & $11 \%$ & 1 \\
\hline & Female & $53 \%$ & 1 & & 3000-6000 RMB & $16 \%$ & 2 \\
\hline \multirow{6}{*}{ Age } & $<18$ & $8 \%$ & 1 & & $6000-10,000$ RMB & $19 \%$ & 3 \\
\hline & $18-30$ & $17 \%$ & 2 & & $10,000-15,000$ RMB & $23 \%$ & 4 \\
\hline & $31-40$ & $21 \%$ & 3 & & $>15,000 \mathrm{RMB}$ & $31 \%$ & 5 \\
\hline & $41-50$ & $18 \%$ & 4 & \multirow{4}{*}{ Family size } & $1-2$ & $33 \%$ & 1 \\
\hline & $51-60$ & $15 \%$ & 5 & & $3-4$ & $41 \%$ & 2 \\
\hline & $>60$ & $21 \%$ & 6 & & $5-6$ & $15 \%$ & 3 \\
\hline \multirow{5}{*}{ Education } & Primary school & $7 \%$ & 1 & & $>6$ & $11 \%$ & 4 \\
\hline & Junior high school & $15 \%$ & 2 & \multirow{4}{*}{$\begin{array}{c}\text { Frequency of } \\
\text { walking exercise } \\
\text { per week }\end{array}$} & $<2$ & $9 \%$ & 1 \\
\hline & Senior high school & $29 \%$ & 3 & & $2-4$ & $14 \%$ & 2 \\
\hline & University & $31 \%$ & 4 & & $5-6$ & $38 \%$ & 3 \\
\hline & Postgraduate & $18 \%$ & 5 & & $>6$ & $39 \%$ & 4 \\
\hline
\end{tabular}




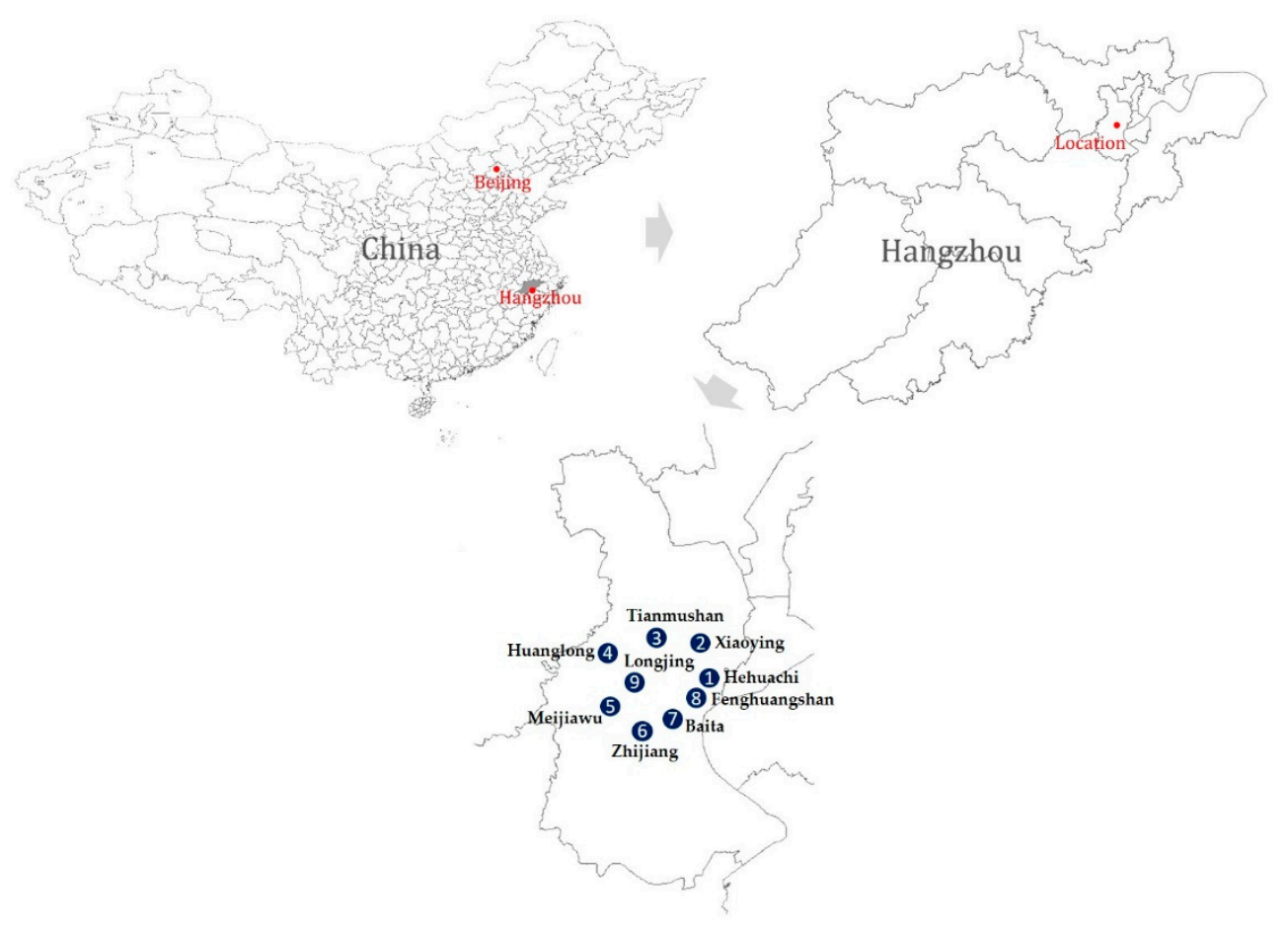

Figure 2. Location of the communities.

\subsection{Research Methods}

\subsubsection{Empirical Research Method}

Based on the conceptual framework, we proposed an empirical research method (Figure 3). We constructed an empirical model from both single and interactive perspectives, trying to reveal the influence mechanism of different GSE measures on mental health. The single perspective selects the two measurement methods of the GSR (Model 1) and GVR (Model 2), and the interactive perspective selects GVE for measurement (Model 3). In addition, greenspace perception, sense of community, and physical activity are selected as the intermediary variables of the impact of GSE on mental health. The greenspace perception may affect the sense of community and physical activity. A higher greenspace perception may increase the sense of community and stimulate more physical activity. Sense of community and physical activity may also influence each other. What needs to be added is that we also included the individual's gender, age, income, education, and other socioeconomic attributes as control variables in the model calculation.

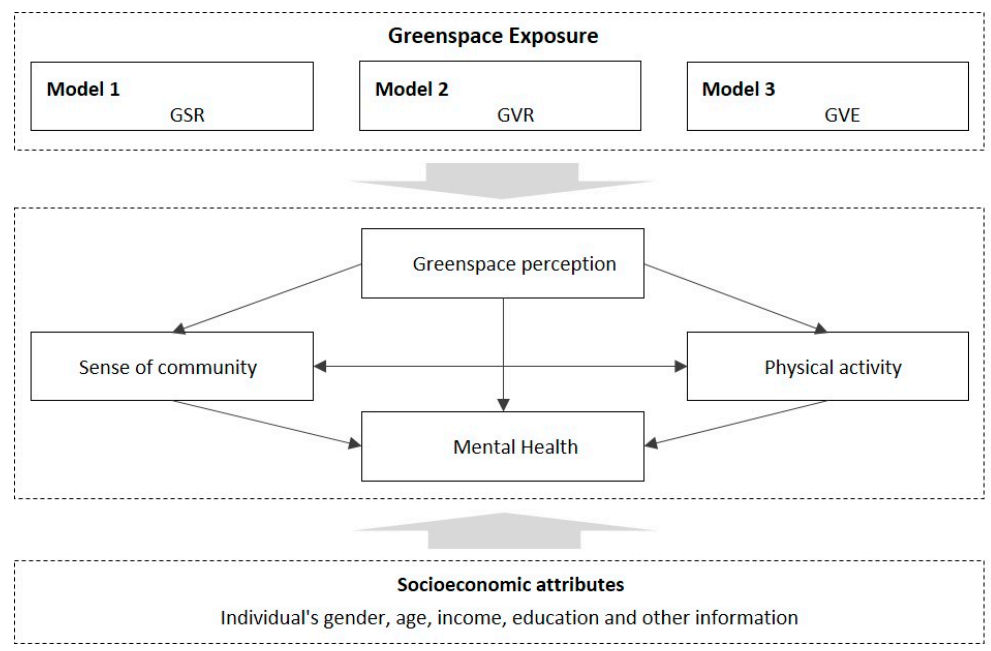

Figure 3. Empirical research method. 


\subsubsection{GVR Measurement}

In this study, a five-term convolutional neural network (CNN) model provided by the Wolfram Neural Net Repository based on MXNet was selected to identify objects in the image (Table 2), and the recognition effects of each model were compared according to the vegetation. Each model training data set comes from Cityscapes, which includes 2000 finely annotated street view images and 6000 roughly annotated street view images. These images are from the street view in downtown Hangzhou. The intersection over union (IoU) is used to judge the accuracy of each model's recognition, which is an indicator that measures the percentage of overlap between the target recognition result and the model prediction result. In addition, the accuracy of the image recognition is measured by calculating the average of different types of IoU indicators (AIoU) [60].

Table 2. The information regarding the different CNNs.

\begin{tabular}{|c|c|c|c|c|c|}
\hline Name & Time & Model Layer & Model Source & Open Source Licenses & Training Dataset \\
\hline Ademxapp Model A1 & 2016 & 141 & github.com/itijyou/ademxapp & Apache 2.0 License & Cityscapes \\
\hline Dilated ResNet-22 & 2017 & 86 & github.com/fyu/drn & BSD 3-Clause License & Dataset \\
\hline Dilated ResNet-38 & 2017 & 142 & github.com/fyu/drn & BSD 3-Clause License & Cityscapes \\
\hline Dilated ResNet-105 & 2017 & 360 & github.com/fyu/drn & BSD 3-Clause License & Dataset \\
\hline Multi-scale Context Aggregation Net & 2016 & 58 & github.com/fyu/dilation & MIT License & Cityscapes \\
\hline
\end{tabular}

From the recognition results, the differences in the recognition effects of the models are mainly in close-range grass and tall vegetation. Ademxapp Model A1 and Multi-scale Context Aggregation Net were not accurate enough to identify distant vegetation, and Dilated ResNet-22 was not accurate enough to identify high vegetation. According to the calculation results of the AIoU (Table 3), Dilated ResNet-105 had the highest recognition accuracy. Therefore, this paper adopted Dilated ResNet-105 to conduct an empirical study on GVR.

Table 3. AIoU comparison by different CNNs for green area identification.

\begin{tabular}{cccccc}
\hline Name & IoU-1 & IoU-2 & IoU-3 & IoU-4 & AIoU \\
\hline Ademxapp Model A1 & 67.3 & 68.34 & 70.23 & 60.13 & 66.50 \\
Dilated ResNet-22 & 59.33 & 64.32 & 73.45 & 65.33 & 65.61 \\
Dilated ResNet-38 & 69.99 & 67.12 & 76.08 & 65.87 & 69.77 \\
Dilated ResNet-105 & 70.99 & 70.41 & 77.02 & 67.87 & 71.57 \\
Multi-scale Context Aggregation Net & 70.43 & 60.72 & 77.4 & 63.55 & 68.03 \\
\hline
\end{tabular}

\subsubsection{GVE Measurement}

Based on the interaction between humans and greenspace, some scholars have proposed a research method for GVE, which is to measure the GVR of people's daytime action routes [56]. First, we selected multiple observation points on the route of action randomly. The GVR of each observation point is the average of the GVR in four directions. If there are less than four images of the observation point, the GVR of the image is recorded as 0 . Therefore, the calculation method of the GVR of a single observation point is:

$$
\mathrm{G}_{\mathrm{VR}}=\frac{\mathrm{G}_{\mathrm{VR} 1}+\mathrm{G}_{\mathrm{VR} 2}+\mathrm{G}_{\mathrm{VR} 3}+\mathrm{G}_{\mathrm{VR} 4}}{N}
$$

Among them : $G_{V R}$ represents the GVR of an observation point; $G_{V R 1}, G_{V R 2}$, $G_{V R 3}$, and $G_{V R 4}$ represent the GVR in four directions; and $N$ represents the number of effective images.

On this basis, the average GVR on a route can be calculated to express the GVE intensity.

$$
\overline{\mathrm{G}_{\mathrm{VR}}}=\frac{\sum_{i=1}^{N} \mathrm{G}_{\mathrm{VRi}}}{N}
$$


Among them: $\overline{G_{V R}}$ represents the average GVR; $G_{V R i}$ represents the GVR of a single observation point; and $\mathrm{N}$ represents the number of observation points.

In addition, GVE is not only related to the average GVR on the route of action, but also related to people's activity time. Therefore, the calculation method of total GVE is:

$$
\mathrm{G}_{\mathrm{VRD}}=\sum_{i=1}^{N} \overline{\mathrm{G}_{\mathrm{VR} i}} T_{i} Q_{i}
$$

Among them: $\overline{G_{V R D}}$ represents the total daily GVE; $\overline{G_{V R i}}$ represents the average GVR of a person on each day action route; $T_{i}$ represents the time of each action; $N$ represents the number of actions per day ; and $Q_{i}$ represents the effective coefficient.

It should be noted that this study only considered people's GVE on fixed routes, and other GVE around the community were not included. In order to facilitate calculation, GVE is normalized in this study.

\subsection{Data Collection}

\subsubsection{Acquisition of Questionnaire Data}

The questionnaire included personal socioeconomic attributes, such as gender, age, height, weight, educational background, average monthly income, etc., to ensure sample diversity. It also included daily exercise locations, walking routes, exercise times, etc., to calculate the GSE.

The Chinese version of the Kessler Psychological Distress Scale (K10) was used to evaluate the mental health status of the respondents. Its main purpose is to evaluate the frequency of specific mental health symptoms of residents in the last week. A total of 10 items are involved, such as fatigue, nervousness, helplessness, irritability, etc. Each evaluation criterion is divided into five levels according to the frequency of symptoms, almost none (five points), occasionally (four points), a small part of the time (three points), most of the time (two points), and all of the time (one point).

Regarding intermediate variables, the Chinese version of the International Physical Activity Questionnaire (IPAQ) was used to record physical activity, and its recording time was in the last week. In the later stage, walking time was selected to calculate the total amount of physical activity per week, and normalized processing was adopted. The sense of community was divided into five options, ranging from no-strong (one point) to very strong (five points). Greenspace perception included four parts: comfort, safety, and accessibility [56], which are divided into five options, ranging from unsatisfactory (one point) to very satisfied (five points).

\subsubsection{Acquisition of GSE Data}

We extended the community boundary by $500 \mathrm{~m}$ to identify the GSR and GVR. Landsat 8 remote sensing image data with an accuracy of $30 \mathrm{~m}$ were used to identify community GSR, which was derived from the geospatial data cloud website (http:/ / www.gscloud.cn/, accessed on 15 March 2021). We input the data into ENVI 5.2 to calculate the Normalized Difference Vegetation Index (NDVI), and the land with an NDVI value greater than 0.5 was considered as greenspace. The community GVR was identified through Baidu Street View data (confidential), and Python was used to obtain and process street view images. We selected observation points every $30 \mathrm{~m}$ on the walking roads around the community, and retrieved images of the corresponding locations. In the end, we obtained 6141 observation points and 15,383 effective images in nine communities (Table 4).

The GVE was calculated with reference to the model in Section 3.2.3, and the effective coefficient $\left(Q_{i}\right)$ was set to 1 [56]. Taking the Longjing community as an example, we selected a resident's travel route, average GVR, and travel time (Table 5), and calculated his GVE value of 1961. Finally, the GVE values of all interviewees were normalized and then incorporated into the model for calculation. 
Table 4. The GSR and GVR of each community.

\begin{tabular}{ccccc}
\hline Name & GSR & GVR & Observation Point & Effective Image \\
\hline Hehuachi & $10.31 \%$ & $20.11 \%$ & 644 & 1582 \\
Xiaoying & $14.11 \%$ & $19.76 \%$ & 535 & 1330 \\
Tianmushan & $10.84 \%$ & $20.17 \%$ & 638 & 1531 \\
Huanglong & $6.91 \%$ & $16.78 \%$ & 791 & 1923 \\
Meijiawu & $27.61 \%$ & $39.42 \%$ & 582 & 1455 \\
Zhijiang & $18.84 \%$ & $24.63 \%$ & 721 & 1882 \\
Baita & $23.55 \%$ & $25.34 \%$ & 802 & 2009 \\
Fenghuangshan & $18.41 \%$ & $21.43 \%$ & 621 & 1592 \\
Longjing & $33.27 \%$ & $35.32 \%$ & 807 & 2079 \\
\hline Note: GSE-greenspace exposure, GSR-greenspace ratio, GVR-green visual ratio, GVE-green visual exposure.
\end{tabular}

Table 5. Example of the calculation process for GVE.

\begin{tabular}{ccc}
\hline Walking Routes & Walking Time & Average GVR \\
\hline Line 1 & 18 & $32.65 \%$ \\
Line 2 & 15 & $32.07 \%$ \\
Line 3 & 7 & $39.98 \%$ \\
Line 4 & 14 & $33.72 \%$ \\
Line 5 & 4 & $35.15 \%$ \\
\hline
\end{tabular}

Note: GVR—green visual ratio, GVE-green visual exposure.

\subsection{Statistical Analyses}

Through the analysis of all variables, no random missing value was greater than $10 \%$, and the expectation maximization algorithm was adopted. All of the variables in the different multivariate models were also included in the calculation process. All continuous variables were basically normally distributed, and they were analyzed using parametric methods, which were reliable for violating the normal distribution hypothesis.

The Pearson correlation coefficient, point bi-serial correlation, and pi coefficient were used in this study to clarify the association pattern of all data. Then, we adopted a multiple linear regression model to analyze the relationship between greenspace exposure, mediators, and mental health. The models were constructed by changing the explanatory variables: GSE in Model 1 took the GSR value; GSE in Model 2 took the GVR value; and GSE in Model 3 took the GVE value. We calculated the tolerance and variance inflation factors, which showed that these models did not have multi-collinearity. Then, we tested a single mediation model linking GSE to mental health through each candidate mediation. Process V3.5 of SPSS was used in this process. The confidence intervals (95\%) of the indirect effects were calculated using the bootstrap bias correction tool.

The structural equation model (SEM) is a multivariate data analysis tool based on the covariance matrix of variables, which can analyze and process multiple dependent variables at the same time. We used the SEM to examine the relationship between different variables, which has been widely used in mental health research. The SEM can be divided into a structural model and a measurement model. The reliability and validity test results of the measurement model showed that the Cronbach's $\alpha$ coefficient of all variables was greater than 0.69 , and the factor loading coefficient of the measurement model was greater than 0.7 , which proved that the reliability and validity were within an acceptable range. In addition, we used AMOS20.0 software to establish the initial model, estimated the data based on the maximum likelihood (ML), and repeated trials and corrections. The results showed that the overall fit index of the three models was good (Table 6). 
Table 6. Goodness-of-fit statistics of the model.

\begin{tabular}{ccccc}
\hline Types & $\chi^{2} /$ DF & GFI & CFI & RMSEA \\
\hline Model 1 & 2.681 & 0.914 & 0.904 & 0.066 \\
Model 2 & 2.723 & 0.909 & 0.911 & 0.072 \\
Model 3 & 2.594 & 0.912 & 0.915 & 0.067 \\
Reference value & $1-3$ & $>0.9$ & $>0.9$ & $<0.08$ \\
\hline
\end{tabular}

\section{Results}

\subsection{Sample Description}

A total of 502 residents participated in the questionnaire survey, and 461 valid questionnaires were finally obtained (Table 7). Participants had a mean age of 42 (range: 14-67 years), 47\% were male, and almost all were community residents (98\%). The detailed characteristics of this sample are shown in Table 7 . We also tested the correlation between the key variables in the data. It should be noted that the correlation between the GSR, GVR, and GVE was tested by taking $500 \mathrm{~m}$ and $1000 \mathrm{~m}$ as buffers, respectively, with reference to the existing literature, and it was found that the correlation between the three was the strongest when the buffer was $500 \mathrm{~m}$. Higher physical activity and greenspace perception were related to higher greenspace exposure.

Table 7. Participant characteristics $(\mathrm{N}=461)$.

\begin{tabular}{|c|c|c|c|c|}
\hline Characteristic & $\mathbf{N}(\%)$ & Mean (SD) & Median (IQR) & Range \\
\hline \multicolumn{5}{|l|}{ Socioeconomic attributes } \\
\hline Age & & $42(5.15)$ & $44(5.56)$ & $14-67$ \\
\hline Men & $217(47)$ & & & \\
\hline \multicolumn{5}{|l|}{ Average monthly salary } \\
\hline$<6000 \mathrm{RMB}$ & $124(27)$ & & & \\
\hline 6000-10,000 RMB & $88(19)$ & & & \\
\hline $10,000-15,000 \mathrm{RMB}$ & $106(23)$ & & & \\
\hline$>15,000 \mathrm{RMB}$ & $143(31)$ & & & \\
\hline \multicolumn{5}{|l|}{ Greenspace exposure } \\
\hline GSR & & $0.182(0.082)$ & $0.184(0.085)$ & $0.069-0.333$ \\
\hline GVR & & $0.248(0.072)$ & $0.214(0.071)$ & $0.168-0.353$ \\
\hline GVE & & $0.525(0.113)$ & $0.529(0.115)$ & $0.311-0.714$ \\
\hline Mental health & & $33.715(5.121)$ & $35.231(5.291)$ & $10-50$ \\
\hline \multicolumn{5}{|l|}{ Candidate mediators } \\
\hline Physical activity & & $0.29(0.24)$ & $0.30(0.25)$ & $0-1$ \\
\hline Sense of community & & $2.59(0.86)$ & $2.61(0.92)$ & $1-5$ \\
\hline \multicolumn{5}{|l|}{ Greenspace perception } \\
\hline Comfort & & $2.53(0.93)$ & $2.56(1.01)$ & $1-5$ \\
\hline Safety & & $2.59(1.02)$ & $2.63(1.06)$ & $1-5$ \\
\hline Accessibility & & $2.98(1.07)$ & $3.01(1.10)$ & $1-5$ \\
\hline
\end{tabular}

Note: GSE—greenspace exposure, GSR—greenspace ratio, GVR—green visual ratio, GVE—green visual exposure, $\mathrm{SD}$-standard deviation, IQR—interquartile range. All continuous variables are assigned a value, and the higher the value of the variable, the higher the value of the factor.

\subsection{Overall Associations between GSE, Candidate Mediators, and Mental Health}

In the model presented in Table 8 , we found that four control variables were statistically significant at the 5\% level, while two were statistically significant at the $10 \%$ level. Gender, education, income, and mental health were negatively correlated, that is, male, high education, and high income people had greater mental health problems [37]. Age, family size, activity frequency, and mental health were positively correlated, that is, people with older age, large family population, and frequent activities had greater mental health [40]. 
Table 8. The estimate parameters of the structure regression model.

\begin{tabular}{|c|c|c|c|}
\hline & Model 1 & Model 2 & Model 3 \\
\hline \multicolumn{4}{|l|}{ Control variables } \\
\hline Gender & $-0.11(-0.27,0.05)$ & $-0.19(-0.31,-0.07)^{b}$ & $-0.56(-1.03,-0.10)^{b}$ \\
\hline Age & $0.14(0.07,0.22)^{b}$ & $0.18(0.10,0.29)$ & $0.21(0.13,0.34)^{b}$ \\
\hline Education & $-0.24(-0.52,0.04)^{b}$ & $-0.31(-0.59,-0.02)$ & $-0.09(-0.15,-0.01)$ \\
\hline Average monthly salary & $-0.03(-0.23,0.16)$ & $-0.19(-0.30,-0.08)^{b}$ & $-0.59(-1.05,-0.13)^{b}$ \\
\hline Family size & $0.02(-0.15,0.19)^{\mathrm{c}}$ & $0.20(0.09,0.38)^{\mathrm{c}}$ & $0.29(0.14,0.43)^{c}$ \\
\hline $\begin{array}{l}\text { Frequency of walking exercise per week } \\
\text { Explanatory variables }\end{array}$ & \multicolumn{2}{|c|}{ Explanatory variables } & $0.56(0.35,0.78)^{\mathrm{c}}$ \\
\hline GSR & $0.15(0.07,0.23)^{b}$ & & \\
\hline GVR & & $0.27(0.05,0.56)^{c}$ & \\
\hline GVE & & & $0.32(0.03,0.61)^{b}$ \\
\hline \multicolumn{4}{|l|}{ Candidate mediators } \\
\hline Physical activity & $-0.11(-0.21,0.02)$ & $0.16(-0.01,0.29)^{b}$ & $0.13(0.02,0.27)^{b}$ \\
\hline Sense of community & $0.31(0.14,0.58)$ & $0.12(0.05,0.24)^{b}$ & $0.18(0.10,0.34)^{b}$ \\
\hline \multicolumn{4}{|l|}{ Greenspace perception } \\
\hline Comfort & $0.31(0.14,0.58)$ & $0.17(0.09,0.36)^{b}$ & $0.28(0.06,0.49)^{b}$ \\
\hline Safety & $0.12(0.01,0.25)^{b}$ & $0.05(-0.01,0.11)$ & $0.14(0.02,0.27)^{b}$ \\
\hline Accessibility & $0.08(-0.01,0.17)$ & $0.25(0.10,0.48)^{b}$ & $0.20(0.07,0.38)^{b}$ \\
\hline
\end{tabular}

Note: GSE—greenspace exposure, GSR—greenspace ratio, GVR—green visual ratio, GVE—green visual exposure. ${ }^{\mathrm{b}} p<0.05,{ }^{\mathrm{c}} p<0.1$.

Specifically, on the basis of controlling socioeconomic attributes, we found the similarities and differences between these three models. The similarity was in the positive correlation between the three types of greenspace exposure and mental health. The difference was in the relationship between candidate mediators and mental health. In Model 1, only the sense of security was positively correlated with mental health; in Model 2, physical activity, sense of community, comfort, and accessibility were positively correlated with mental health, which indicated that the effective mediating factors were more diverse after the measurement of greenspace exposure changed from a plane to three-dimensional [38]. In Model 3, physical activity, sense of community, comfort, safety, and accessibility were positively correlated with mental health, especially the three components of greenspace perception. This indicated that when the measurement of greenspace exposure was shifted to the actual reception of people, the perception ability of greenspace was more significant [56].

We analyzed the associations between the different GSE and candidate mediators (Table 9). In Model 1, the GSR reached statistical significance with all candidate mediations, but a higher GSR was associated with a lower greenspace security. In Model 2, the GVR reached statistical significance with all candidate intermediaries, but a higher GVR was associated with lower safety and accessibility of greenspace. In Model 3, GVE and all candidate mediations reached statistical significance, which was positively correlated.

Table 9. Associations between GSE and candidate mediators.

\begin{tabular}{|c|c|c|c|c|c|}
\hline \multirow{2}{*}{ Greenspace Measure } & \multirow{2}{*}{ Physical Activity } & \multirow{2}{*}{ Sense of Community } & \multicolumn{3}{|c|}{ Greenspace Perception } \\
\hline & & & Comfort & Safety & Accessibility \\
\hline Model 1 & & & & & \\
\hline GSR & $0.11(0.03,0.19)^{b}$ & $0.13(0.06,0.21)^{b}$ & $0.01(0.001,0.02)^{b}$ & $-0.02(-0.03,-0.01)^{b}$ & $0.03(0.01,0.05)^{b}$ \\
\hline 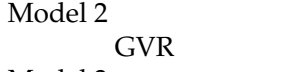 & $0.14(0.08,0.20)^{b}$ & $0.08(-0.02,0.16)^{b}$ & $0.22(0.11,0.39)^{b}$ & $-0.18(-0.28,-0.08)^{b}$ & $-0.10(-0.19,-0.01)^{b}$ \\
\hline $\begin{array}{l}\text { Model } 3 \text { GVE } \\
\end{array}$ & $0.33(0.10,0.56)^{b}$ & $0.42(0.24,0.59)^{b}$ & $0.37(0.15,0.58)^{b}$ & $0.35(0.12,0.58)^{b}$ & $0.44(0.26,0.61)^{b}$ \\
\hline
\end{tabular}

Note: GSE-greenspace exposure, GSR—greenspace ratio, GVR—green visual ratio, GVE—green visual exposure. Non-standardized linear regression coefficients with $95 \%$ confidence intervals. ${ }^{\mathrm{b}} p<0.05$. 


\subsection{Main Analysis}

In the initial SEM test, the influence of a series of mediators was considered, and the fit indices were not significant, for example, RMSEA $=0.083(<0.08)$ in Model 1 . The $\chi^{2} /$ DF in Model 2 was $3.02(1-3)$. The RMSEA in Model $3=0.086(<0.08)$. Therefore, this study followed the iterative process of model re-specification, adding multiple covariance links between error items and deleting confusing and unimportant paths. Through some selected criteria, the final three models had acceptable adaptability to the data, and the fit indices met the requirements.

When controlling for socioeconomic attributes, according to the pathway parameters of the effects of different GSE modalities on mental health (Table 10), we found that the GSE in the three models all presented a positive impact on mental health. This suggests that GSE can improve mental health, which was also consistent with the existing theories [61]. However, when each model was analyzed separately, there were significant differences in the influence path of different GSE modalities on mental health.

Table 10. Total, direct, and indirect associations of GSE with mental health in the structural equation model.

\begin{tabular}{cccc}
\hline Influence Effect & Model 1 & Model 2 & Model 3 \\
\hline Total effect & $0.17(0.05,0.43)^{\mathrm{b}}$ & $0.30(0.09,0.54)^{\mathrm{b}}$ & $0.38(0.17,0.68)^{\mathrm{b}}$ \\
Direct effect & $0.17(0.05,0.43)^{\mathrm{b}}$ & $0.23(0.08,0.53)^{\mathrm{c}}$ & $0.27(0.12,0.62)^{\mathrm{b}}$ \\
Total indirect effect & - & $0.07(0.01,0.18)^{\mathrm{b}}$ & $0.11(0.05,0.32)^{\mathrm{b}}$ \\
\hline
\end{tabular}

Note: Non-standardized linear regression coefficients with $95 \%$ confidence intervals. ${ }^{\mathrm{b}} p<0.05,{ }^{\mathrm{c}} p<0.1$.

By comparing the results of Model 1 and Model 2 (Figure 4), when the measurement method was the GSR, GSE only had a direct effect on mental health. When the measurement method was adjusted to the GVR, the direct effect coefficient of GSE on mental health increased, and the indirect influence path of greenspace perception and sense of community as mediating variables appeared [62]. From the results of Model 3, when the GSE measurement took full account of the residents' activities, the total and direct effects on mental health were further increased, and greenspace perception, sense of community, and physical activity became mediating variables for the impact of GVE on mental health.
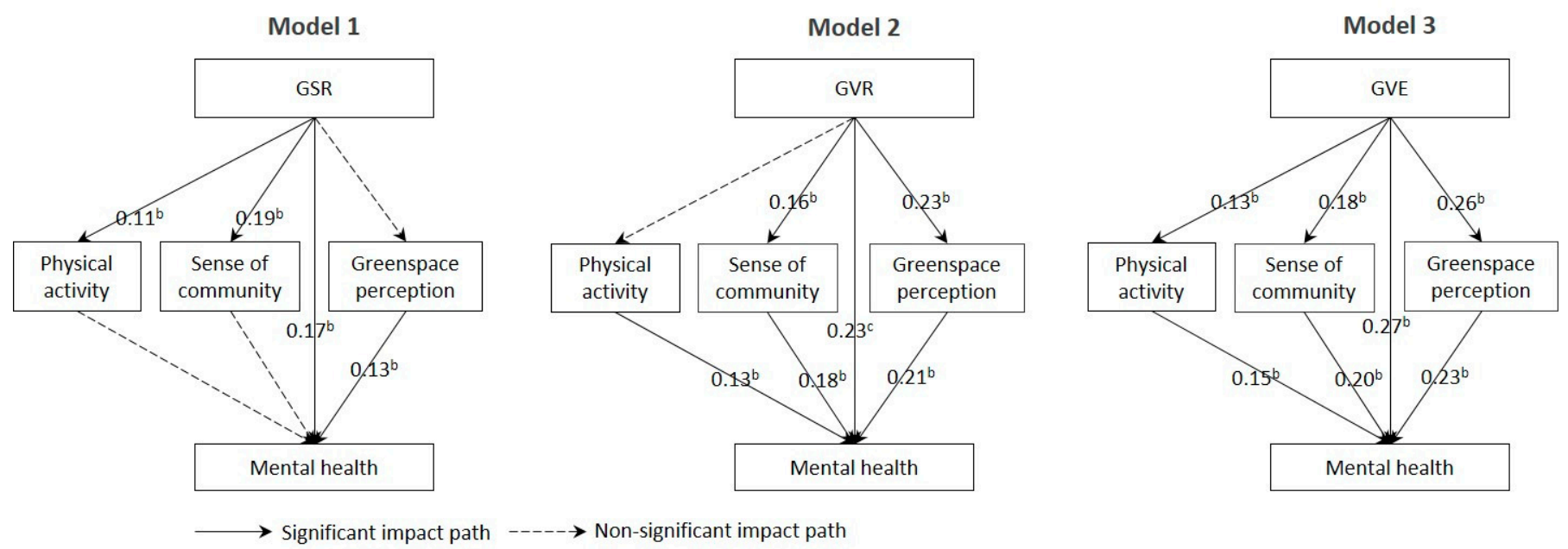

Figure 4. Structural model showing the estimated paths linking GSE to mental health. Note: GSE-greenspace exposure, GSR - greenspace ratio, GVR - green visual ratio, GVE-green visual exposure. The unstandardized regression weights are given for each path. The measurement model, control variables, covariance, and error terms are not shown here to enhance readability. ${ }^{\mathrm{b}} p<0.05,{ }^{\mathrm{c}} p<0.1$. 


\section{Discussion}

Through a survey of nine communities in Hangzhou, China, we studied the influence paths of different GSE modalities on mental health, and considered some candidate mediators that were rarely mentioned before. We think this is innovative. The greenspace analysis methods based on remote sensing data are widely used by medical and sociological scholars [63-65]. We adopted another research method to measure GSE, namely machine deep learning and Baidu Street View data, and incorporated residents' activity into the calculation. This is also innovative to a certain extent.

\subsection{Analysis of Research Methods from a Comparative Perspective}

Is there any difference in the influence paths of different GSE modalities on mental health? With this question in mind, we chose three different exposure modes (i.e., the GSR, GVR, and GVE) to analyze their influence paths on mental health. Through the comparison between Model 1 and Model 2, the GVR is more closely related to mental health than the GSR. This is also consistent with some scholars' view that more visual perception can reduce the probability of suffering from mental illness, as explained by attention restoration and stress recover theory [66]. Based on this conclusion or the views of other scholars [67], we believe that community GVR measurement based on street view images can reflect the actual situation of GSE, because remote sensing data make it difficult to identify small numbers or vertical greens (e.g., green walls). These may also benefit mental health [13]. As argued by other studies, the eye-level measures can better capture the human perception of nature that is related to mental health [68]. Based on these analyses, we boldly assume that, as street view databases, such as Tencent, Baidu, and Google become more refined and available, street view images and machine deep learning will become increasingly popular in the evaluation and measurement of community greenspace. Overall, the research potential in this area is huge.

By comparing the three models, we find that, as the GSE measure turns to actual reception, its influence path on mental health becomes more complex and diversified [69]. This finding validates our initial hypothesis that all three methods quantify different aspects of greenspace, and that self-reported (actually received) GSE is stronger in all associations with mental health $[70,71]$. This also reflects a fact that previous satellite or street view measurement methods are not enough, and self-report measurement methods should be combined with satellite (street view) measurement methods. For example, the GVE measurement in this study has realized the integration of the street view and resident reports to better capture the actual interaction between people and greenspace.

\subsection{Interpretation of the Research Results Based on Existing Findings}

This research is based on the hypothesis that GSE is beneficial to mental health. Some scholars have also proven that this process will be affected by the measurement of exposure [72,73]. Taking nine communities in Hangzhou as samples, this study investigated the relationship between different GSE, candidate mediators, and mental health. For objective greenspace measurement of the GSR, we found only one mechanism that directly affected mental health. For the measurement of the GVR and GVE based on the interaction between human and greenspace, we found two mechanisms that affected mental health directly and indirectly.

More specifically (Figure 4), in Model 1, the GSR has only a direct effect on mental health, while the indirect effects of greenspace perception, sense of community, and physical activity as mediators are not significant, which is also consistent with existing cognition [69]. However, in Model 2, the GVR extends the measurement of greenspace to the threedimensional perception level, which directly reflects people's perception of greenspace from the perspective of interaction [63], and the indirect effect of greenspace perception and sense of community as mediators is significant. In other words, three-dimensional greenspace can provide residents with a richer sense of greenspace, which is also more conducive to mental health. This is an important proof of GSE measurement from plane to 
stereo [67]. At the same time, the three-dimensional greenspace can increase the sense of community. When the community's cultural identity, neighborhood relationship, and daily interaction are more harmonious, the mental health promotion effect of the GVR is more obvious [74]. In some studies, the sense of community was identified as a mediator [75], but in other studies, it was not [76]. This may be related to the way in which the sense of community is used as a mediator (single or intersecting), or to the measurement of greenspace [63]. However, the indirect influence path of the sense of community as a mediator in Model 2 has been confirmed, which is also an enrichment of the existing theory.

When we study the influence pathways of GVE on mental health (i.e., comprehensively considering factors such as the duration and route of people's activities in the greenspace), the influence path of physical activity as a mediator becomes significant, indicating that physical activity in the greenspace is more conducive to mental health [63]. This provides further evidence that regular participation in outdoor activities (in greenspaces) can promote mental health [77]. Therefore, for greenspace practice, residents' activities can be promoted by providing more diversified facilities to achieve the purpose of improving mental health, such as neighborhood interaction activities [77-79]. In addition, some studies have also mentioned that physical activity cannot be the mediator of the greenspace on mental health $[75,76]$, because the intermediary model misinterprets the orthogonal path [80]. For this reason, we boldly propose that the indirect influence of physical activity as an intermediary can be significant only when the measurement of GSE is actually received.

\subsection{Public Heath Implication}

Policy formulation of urban greenspace needs to be based on science [81]. Clarifying the different GSE and identifying relevant mediators can support social interventions outside of urban planning. Studying how mediators interact with greenspace and mental health can help improve public health. For example, if the sense of community can exert a positive impact on the relationship between GSE and mental health, then interventions can enhance the design and construction of environments that foster a sense of community. At the same time, scholars should also find a clear way to communicate the complex findings of the research to greenspace management and practice departments, to provide a solid support for decision-makers.

This research has a significant practical significance for China and even other countries. Urban planning and design in China only include the GSR, but ignores other control indicators. In the design process of greenspace, the sense of community and greenspace perception is often ignored, and even sports facilities are deficient. All of these cause the impact of greenspace on mental health to be overly dependent on visual reception and ignore other pathways. Therefore, this study not only further enriches and expands the measures of urban planning and social intervention, but also provides multiple ideas for the policy formulation of greenspace, to realize the mental health promotion of urban residents.

\subsection{Strength and Limitations}

The advantages of this paper are reflected in many aspects. First, most of the research cases on the impact of GSE on mental health are in European and American countries [82], and there are few cases in China, although the existing results of the Hangzhou case need to be further verified. Second, we propose a variety of greenspace measurement methods innovatively, such as GVE, based on the perspective of interaction between humans and greenspace. At the same time, we have also verified the indirect pathways of various mediators' influence on mental health, and some mediators (landscape perception and sense of community) are even beyond the focus of medical research, to a certain extent [83]. Thirdly, through refined research and interviews, we tried our best to make the research data more accurate, rather than using rough records [83]. For example, the members of the research team draw out all of the activity routes of the interviewees (461) in the past week one by one. 
In addition, this study also has some limitations. First, due to the difficulty of obtaining street view images and remote sensing data, there is a certain time error (one year). Second, the data obtained through interviews and questionnaires also have certain limitations. To give a simple example, we evaluated the health benefits of greenspace through field observations, self-reports, and questionnaires, which can only be completed within a limited time, so we cannot fully evaluate their representativeness. Thirdly, the conceptual framework proposed in this paper needs further improvement and verification. Finally, we applied a cross-sectional study design, the shortcomings of which are well-known, among which the causal analysis is to be improved.

\section{Conclusions}

This paper reveals the influence mechanism of different GSE methods on mental health through the case study of Hangzhou, China. Different from the previous measurement of the GSR based on remote sensing data, we used questionnaire data, Baidu street view data, and a convolutional neural network model to measure the GVR and GVE.

We prove that GSE has a certain positive effect on mental health. However, through the comparative analysis between different models, we find that the GSR recognition of satellite images may not be able to capture people's perception of greenspace. Therefore, the GSR has only a single direct influence mechanism on mental health. When we consider the effects of the GVR and GVE on mental health from the perspective of human/greenspace interaction, the influence mechanism becomes more complex. Greenspace perception, sense of community, and physical activity can be used as intermediary mediators, and the influence mechanism also presents the characteristics of direct and indirect coexistence.

In addition, we think that how to translate the research results into the practice of community greenspace is also very meaningful. First, the greenspace design of the community should not only focus on the GSR, but also include the GVR and GVE in the control indicators to create more abundant greenspace forms and realize residents' more direct contact with greenspace. Second, the relevant mediators between greenspace and mental health proposed in this study have guiding significance for community planning and social intervention. For example, greenspace in the community should provide neighborhood communication space for residents, which is more conducive to mental health. Third, we believe that more relevant mediators should be included in empirical studies to provide more innovative ideas for greenspace planning and social intervention.

Author Contributions: J.L. and X.L. designed the research and participated in the questionnaires and interviews. J.L. wrote the first draft of the paper, X.L. and N.Y. processed and analyzed the data, and Y.S. contributed to street view image analysis and machine deep learning. All authors have read and agreed to the published version of the manuscript.

Funding: The research described in this paper was financially supported by the Natural Science Foundation of China (Grant Nos. 41471133).

Informed Consent Statement: Informed consent was obtained from all subjects involved in the study.

Data Availability Statement: The data presented in this study are available on request from the corresponding author.

Acknowledgments: The research described in this paper was financially supported by the Natural Science Foundation of China (Grant Nos. 41471133).

Conflicts of Interest: None declared.

\section{References}

1. Blanco, H.; Alberti, M.; Forsyth, A.; Krizek, K.; Rodríguez, D.; Talen, E.; Ellis, C. Hot, congested, crowded and diverse: Emerging research agendas in planning. Prog. Plan. 2009, 71, 153-205. [CrossRef]

2. Zhang, J.; Chaaban, J. The economic cost of physical inactivity in china. Prev. Med. 2013, 56, 75-78. [CrossRef]

3. Weich, S.; Blanchard, M.; Prince, M.; Burton, E.; Erens, B.; Sproston, K. Mental health and the built environment: Cross-sectional survey of individual and contextual risk factors for depression. Br. J. Psychiatry 2002, 180, 428. [CrossRef] 
4. Lu, Y.; Xu, J.; Wang, H.; Liu, X.; Li, W. Distribution, sources and health risk assessment of contaminations in water of urban park: A case study in Northeast China. Environ. Geochem. Health 2019, 41, 2473-2489. [CrossRef]

5. Twohig-Bennett, C.; Jones, A. The health benefits of the great outdoors: A systematic review and meta-analysis of greenspace exposure and health outcomes. Environ. Res. 2018, 166, 628-637. [CrossRef]

6. Taylor, L.; Hochuli, D.F. Defining greenspace: Multiple uses across multiple disciplines. Landsc. Urban Plan. 2017, 158, 25-38. [CrossRef]

7. Dennis, M.; James, P. Evaluating the relative influence on population health of domestic gardens and green space along a rural-urban gradient. Landsc. Urban Plan. 2017, 157, 343-351. [CrossRef]

8. Genter, C.; Roberts, A.; Richardson, J.; Sheaff, M. The contribution of allotment gardening to health and wellbeing: A systematic review of the literature. Br. J. Occup. Ther. 2015, 78, 593-605. [CrossRef]

9. Nordh, H.; Evensen, K.H.; Skår, M. A peaceful place in the city-A qualitative study of restorative components of the cemetery. Landsc. Urban Plan. 2017, 167, 108-117. [CrossRef]

10. Takano, T.; Nakamura, K.; Watanabe, M. Urban residential environments and senior citizens' longevity in megacity areas: The importance of walkable green spaces. J. Epidemiol. Community Health 2002, 56, 913-918. [CrossRef] [PubMed]

11. Latkin, C.A.; Curry, A.D. Stressful neighborhoods and depression: A prospective study of the impact of neighborhood disorder. J. Health Soc. Behav. 2003, 44, 34-44. [CrossRef]

12. Mireia, G.; Margarita, T.M.; David, M.; Payam, D.; Joan, F.; Antoni, P.; Mark, J. Mental Health Benefits of Long-Term Exposure to Residential Green and Blue Spaces: A Systematic Review. Int. J. Environ. Res. Public Health 2015, 12, 4354-4379. [CrossRef]

13. Mitchell, R.; Popham, F. Effect of exposure to natural environment on health inequalities: An observational population study. Lancet 2008, 372, 1655-1660. [CrossRef]

14. Nutsford, D.; Pearson, A.L.; Kingham, S. An ecological study investigating the association between access to urban green space and mental health. Public Health 2013, 127, 1005-1011. [CrossRef] [PubMed]

15. Berg, A.E.V.D.; Winsum-Westra, M.V.; Vries, S.D.; Dillen, S.M.V. Allotment gardening and health: A comparative survey among allotment gardeners and their neighbors without an allotment. Environ. Health 2010, 9, 1-12. [CrossRef]

16. Bell, S.D.; White, M.; Griffiths, A.; Darlow, A.; Lovell, R. Spending time in the garden is positively associated with health and wellbeing: Results from a national survey in England. Landsc. Urban Plan. 2020, 200, 1-10. [CrossRef]

17. Labib, S.M.; Lindley, S.; Huck, J.J. Spatial dimensions of the influence of urban green-blue spaces on human health: A systematic review. Environ. Res. 2020, 180, 108869. [CrossRef]

18. Howard, F.; Bratman, G.N.; Breslow, S.J.; Cochran, B.; Kahn, P.H., Jr.; Lawler, J.; Levin, P.S.; Tandon, P.S.; Varanasi, U.; Wolf, K.L.; et al. Nature Contact and Human Health: A Research Agenda. Environ. Health Perspect. 2017, 125, 075001. [CrossRef]

19. Beyer, K.M.; Kaltenbach, A.; Szabo, A.; Bogar, S.; Nieto, F.J.; Malecki, K.M. Exposure to Neighborhood Green Space and Mental Health: Evidence from the Survey of the Health of Wisconsin. Int. J. Environ. Res. Public Health 2014, 11, 3453-3472. [CrossRef]

20. Payam, D.; Christina, T.; Marisa, E.; Llop, S.; Dalmau-Bueno, A.; López-Vicente, M.; Valentín, A.; Keijzer, C.D.; FernándezSomoano, A.; Lertxundi, N.; et al. Lifelong Residential Exposure to Green Space and Attention: A Population-based Prospective Study. Environ. Health Perspect. 2017, 125, 097016. [CrossRef]

21. Thompson, C.W.; Roe, J.; Aspinall, P.; Mitchell, R.; Clow, A.; Miller, D. More green space is linked to less stress in deprived communities: Evidence from salivary cortisol patterns. Landsc. Urban Plan. 2012, 105, 221-229. [CrossRef]

22. Hazer, M.; Formica, M.K.; Dieterlen, S.; Morley, C.P. The relationship between self-reported exposure to greenspace and human stress in Baltimore, MD. Landsc. Urban Plan. 2018, 169, 47-56. [CrossRef]

23. Dzhambov, A.M.; Iana, M.; Tilov, B.G.; Dimitrova, D.D. Residential green space might modify the effect of road traffic noise exposure on general mental health in students. Urban For. Urban Green. 2018, 34, 233-239. [CrossRef]

24. Schwartz, R.M.; Gillezeau, C.; Liu, B.; Lieberman-Cribbin, W. Longitudinal impact of hurricane sandy exposure on mental health symptoms. Int. J. Environ. Res. Public Health 2017, 14, 957. [CrossRef]

25. Bowler, D.E.; Buyung-Ali, L.M.; Knight, T.M.; Pullin, A.S. A systematic review of evidence for the added benefits to health of exposure to natural environments. BMC Public Health 2010, 10, 456. [CrossRef] [PubMed]

26. Capaldi, C.A.; Dopko, R.L.; Zelenski, J.M. The relationship between nature connectedness and happiness: A meta-analysis. Front. Psychol. 2014, 5, 976. [CrossRef]

27. Johnson, B.S.; Malecki, K.M.; Peppard, P.E.; Beyer, K.M.M. Exposure to neighborhood green space and sleep: Evidence from the survey of the health of Wisconsin. Sleep Health 2018, 4, 413-419. [CrossRef]

28. Carpenter, M. From healthful exercise to nature on prescription: The politics of urban green spaces and walking for health. Landsc. Urban Plan. 2013, 118, 120-127. [CrossRef]

29. Allen, J.O.; Alaimo, K.; Elam, D.; Perry, E. Growing Vegetables and Values: Benefits of Neighborhood-Based Community Gardens for Youth Development and Nutrition. J. Hunger. Environ. Nutr. 2008, 3, 418-439. [CrossRef]

30. Mangadu, T.; Kelly, M.; Orezzoli, M.; Gallegos, R.; Matharasi, P. Best practices for community gardening in a US-Mexico border community. Health Promot. Int. 2017, 32, 1001-1014. [CrossRef]

31. Clair, R.S.; Hardman, M.; Armitage, R.P.; Sherriff, G. The trouble with temporary: Impacts and pitfalls of a meanwhile community garden in Wythenshawe, South Manchester. Renew. Agric. Food Syst. 2017, 33, 548-557. [CrossRef]

32. Dyg, P.M.; Christensen, S.; Peterson, C.J. Community gardens and wellbeing amongst vulnerable populations: A thematic review. Health Promot. Int. 2020, 35, 790-803. [CrossRef] 
33. Ghimire, R.; Ferreira, S.; Green, G.T.; Poudyal, N.C.; Cordell, H.K.; Thapa, J.R. Green Space and Adult Obesity in the United States. Ecol. Econ. 2017, 136, 201-212. [CrossRef]

34. Park, J.J.; O'Brien, L.; Roe, J. The natural outdoors and health: Assessing the value and potential contribution of secondary public data sets in the UK to current and future knowledge. Health Place 2011, 17, 269-279. [CrossRef]

35. Dubová, L.; Macháč, J. Improving the quality of life in cities using community gardens: From benefits for members to benefits for all local residents. GeoScape 2019, 13, 68-78. [CrossRef]

36. Ebisu, K.; Holford, T.R.; Bell, M.L. Association between greenness, urbanicity, and birth weight. Sci. Total Environ. 2016, 542, 750-756. [CrossRef] [PubMed]

37. Thompson, C.L.; Aspinall, P.; Roe, J.; Robertson, L.; Miller, D. Mitigating Stress and Supporting Health in Deprived Urban Communities: The Importance of Green Space and the Social Environment. Int. J. Environ. Res. Public Health 2016, 13, 440. [CrossRef] [PubMed]

38. Mourao, I.; Moreira, M.C.; Almeida, T.C.; Brito, L.M. Perceived changes in well-being and happiness with gardening in urban organic allotments in Portugal. Int. J. Sustain. Dev. World Ecol. 2019, 26, 79-89. [CrossRef]

39. Egli, V.; Oliver, M.; Tautolo, E.S. The development of a model of community garden benefits to wellbeing. Prev. Med. Rep. 2016, 3, 348-352. [CrossRef]

40. Baur, J. Campus community gardens and student health: A case study of a campus garden and student well-being. J. Am. Coll. Health 2020, 4, 1-8. [CrossRef] [PubMed]

41. Jane, W.; Frances, C.; Michael, R. Growing or connecting? An urban food garden in Johannesburg. Health Promot. Int. 2010, 25, 33-41. [CrossRef]

42. Wolch, J.R.; Byrne, J.; Newell, J.P. Urban green space, public health, and environmental justice: The challenge of making cities just green enough. Landsc. Urban Plan. 2014, 125, 234-244. [CrossRef]

43. Kingsley, J.; Townsend, M. 'Dig in' to social capital: Community gardens as mechanisms for growing urban social connectedness. Urban Policy Res. 2006, 24, 525-537. [CrossRef]

44. Firth, C.; Maye, D.; Pearson, D. Developing "community" in community gardens. Local Environ. 2011, 16, 555-568. [CrossRef]

45. Kondo, M.C.; Low, S.C.; Henning, J.; Branas, C.C. The Impact of Green Stormwater Infrastructure Installation on Surrounding Health and Safety. Am. J. Public Health 2015, 105, 114-121. [CrossRef] [PubMed]

46. Hardin-Fanning, F.; Adegboyega, A.O.; Rayens, M.K. Adolescents' Perceptions of a Gardening Activity at a Juvenile Justice Center. J. Holist. Nurs. 2018, 36, 170-178. [CrossRef] [PubMed]

47. Gilchrist, K.; Brown, C.; Montarzino, A. Workplace settings and wellbeing: Greenspace use and views contribute to employee wellbeing at peri-urban business sites. Landsc. Urban Plan. 2015, 138, 32-40. [CrossRef]

48. Egerer, M.; Ordóñez, C.; Lin, B.B.; Kendal, D. Multicultural gardeners and park users benefit from and attach diverse values to urban nature spaces. Urban For. Urban Green. 2019, 46, 126445. [CrossRef]

49. Schoen, V.; Caputo, S.; Blythe, C. Valuing Physical and Social Output: A Rapid Assessment of a London Community Garden. Sustainability 2020, 12, 5452. [CrossRef]

50. Selmi, W.; Weber, C.; Rivière, E.; Nadège, B. Air pollution removal by trees in public green spaces in Strasbourg city, France. Urban For. Urban Green. 2016, 17, 192-201. [CrossRef]

51. Barthel, S.; Folke, C.; Colding, J. Social-ecological memory in urban gardens-retaining the capacity for management of ecosystem services. Glob. Environ. Chang. 2010, 20, 255-265. [CrossRef]

52. Yang, C.; He, X.; Wang, R.; Yan, F.; Yu, L.; Bu, K.; Yang, J.; Chang, L.; Zhang, S. The Effect of Urban Green Spaces on the Urban Thermal Environment and Its Seasonal Variations. Forests 2017, 8, 153. [CrossRef]

53. Bendt, P.; Barthel, S.; Colding, J. Civic greening and environmental learning in public-access community gardens in Berlin. Landsc. Urban Plan. 2013, 109, 18-30. [CrossRef]

54. Aoki, Y. Relationship between perceived greenery and width of visual fields. J. Jpn. Inst. Landsc. Arch. 1987, 51, 1-10. [CrossRef]

55. Yagawa, M.; Amura, A. Human's sense of time: As an index of the sympathy between man and environment. AIJ J. Technol. Design 1999, 5, 155-158. [CrossRef]

56. Song, Y.; Huang, B.; Cai, J.; Chen, B. Dynamic assessments of population exposure to urban greenspace using multi-source big data. Sci. Total Environ. 2018, 634, 1315. [CrossRef] [PubMed]

57. Zhang, L.; Zhou, S.H.; Kwan, M.; Chen, F.; Lin, R. Impacts of individual daily greenspace exposure on health based on individual activity space and structural equation modeling. Int. J. Environ. Res. Public Health 2018, 15, 2323. [CrossRef]

58. Zhou, C.; Chu, J.; Wang, T. Reliability and Validity of 10-item Kessler Scale (K10) Chinese Version in Evaluation of Mental Health Status of Chinese Population. J. Clin. Psychol. 2008, 16, 627-629.

59. Lachowycz, K.; Jones, A.P. Towards a better understanding of the relationship between greenspace and health: Development of a theoretical framework. Landsc. Urban Plan. 2013, 118, 62-69. [CrossRef]

60. Riaz, H.; Park, J.H.; Kim, P.; Kim, J. Retinal Healthcare Diagnosis Approaches with Deep Learning Techniques. J. Med. Imag. Health Infor. 2021, 11, 846-855. [CrossRef]

61. Alcock, I.; White, M.P.; Lovell, R.; Higgins, S.L.; Osborne, N.J.; Husk, K.; Wheeler, B.W. What accounts for 'England's green and pleasant land'? A panel data analysis of mental health and land cover types in rural England. Landsc. Urban Plan. 2015, 142, 38-46. [CrossRef] 
62. Wen, Z.; Ye, B. Analyses of mediating effects: The development of methods and models. Adv. Psychol. Sci. 2014, $22,731-745$. [CrossRef]

63. Dzhambov, A.; Hartig, T.; Markevych, I.; Tilov, B.; Dimitrova, D. Urban residential greenspace and mental health in youth: Different approaches to testing multiple pathways yield different conclusions. Environ. Res. 2018, 160, 47-59. [CrossRef] [PubMed]

64. Groenewegen, P.P.; Zock, J.P.; Spreeuwenberg, P.; Helbich, M.; Dijst, M. Neighbourhood social and physical environment and general practitioner assessed morbidity. Health Place 2017, 49, 68-84. [CrossRef]

65. Nutsford, D.; Pearson, A.L.; Kingham, S.; Reitsma, F. Residential exposure to visible blue space (but not green space) associated with lower psychological distress in a capital city. Health Place 2016, 39, 70-78. [CrossRef]

66. Ulrich, R.S.; Simons, R.F.; Losito, B.D.; Fiorito, E.; Zelson, M. Stress recovery during exposure to natural and urban environments. J. Environ. Psychol. 1991, 11, 201-230. [CrossRef]

67. Bell, S.D.; Grahamb, H.; Jarvisb, S.; Whitea, P. The importance of nature in mediating social and psychological benefits associated with visits to freshwater blue space. Landsc. Urban Plan. 2017, 167, 118-127. [CrossRef]

68. Kumakoshi, Y.; Chan, S.Y.; Koizumi, H.; Li, X.; Yoshimura, Y. Standardized green view index and quantification of different metrics of urban green vegetation. Sustainability 2020, 12, 7434. [CrossRef]

69. Cusack, L. Associations between multiple green space measures and birth weight across two US cities. Health Place 2017, 47, 36-43. [CrossRef] [PubMed]

70. Lu, Y.; Sarkar, C.; Xiao, Y. The effect of street-level greenery on walking behavior: Evidence from Hong Kong. Soc. Sci. Med. 2018, 208, 41-49. [CrossRef] [PubMed]

71. Dadvand, P.; Hariri, S.; Abbasi, B.; Heshmat, R.; Qorbani, M.; Motlagh, M.E.; Basagaña, X.; Kelishadi, R. Use of green spaces, self-satisfaction and social contacts in adolescents: A population-based CASPIAN-V study. Environ. Res. 2019, 168, 171-177. [CrossRef]

72. Zock, J.P.; Verheij, R.; Helbich, M.; Volker, B.; Spreeuwenberg, P.; Strak, M.; Janssen, N.A.H.; Dijst, M.; Groenewegen, P. The impact of social capital, land use, air pollution and noise on individual morbidity in Dutch neighbourhoods. Environ. Int. 2018, 121, 453-460. [CrossRef]

73. Kuo, F.E.; Sullivan, W.C.; Coley, R.L.; Brunson, 1. Fertile Ground for Community: Inner-City Neighborhood Common Spaces. Am. J. Community Psychol. 1998, 26, 823-851. [CrossRef]

74. Dadvand, P.; Bartoll, X.; Basagaa, X.; Dalmau-Bueno, A.; Nieuwenhuijsen, M.J. Green spaces and General Health: Roles of mental health status, social support, and physical activity. Environ. Int. 2016, 91, 161-167. [CrossRef] [PubMed]

75. Triguero-Mas, M.; Dadvand, P.; Cirach, M.; David, M.; Medina, A.; Mompart, S.; Basagaña, X.; Gražulevičienè, R.; Nieuwenhuijsen, M.J. Natural outdoor environments and mental and physical health: Relationships and mechanisms. Environ. Int. 2015, 77, 35-41. [CrossRef] [PubMed]

76. Hartig, T. Green space, psychological restoration, and health inequality. Lancet 2008, 372, 1614-1615. [CrossRef]

77. Buchecker, M.; Degenhardt, B. The effects of urban inhabitants' nearby outdoor recreation on their well-being and their psychological resilience. J. Outdoor Recreat. Tour. 2015, 10, 55-62. [CrossRef]

78. Dahlkvist, E.; Hartig, T.; Nilsson, A.; Högberg, H.; Skovdahl, K.; Engström, M. Garden greenery and the health of older people in residential care facilities: A multi-level cross-sectional study. J. Adv. Nurs. 2016, 72, 2065-2076. [CrossRef] [PubMed]

79. Vries, S.D.; Van Dillen, S.M.E.; Groenewegen, P.P.; Spreeuwenberg, P. Streetscape greenery and health: Stress, social cohesion and physical activity as mediators. Soc. Sci. Med. 2013, 94, 26-33. [CrossRef]

80. Janse, G.; Konijnendijk, C.C. Communication between science, policy and citizens in public participation in urban forestryExperiences from the Neighbourwoods project. Urban For. Urban Green. 2007, 6, 23-40. [CrossRef]

81. Bosch, M.V.D.; Sang, A.O. Urban natural environments as nature-based solutions for improved public health-A systematic review of reviews. Environ. Res. 2017, 158, 373-384. [CrossRef] [PubMed]

82. Amanda, R.; Pearson, A.L.; Dougherty, B.V.; Ashton, S.; Nick, W. Systematic review of the use of Google Street View in health research: Major themes, strengths, weaknesses and possibilities for future research. Health Place 2018, 52, 240-246. [CrossRef]

83. Larkin, A.; Geddes, J.A.; Martin, R.V.; Xiao, Q.; Yang, L.; Marshall, J.D.; Brauer, M.; Hystad, P. Global Land Use Regression Model for Nitrogen Dioxide Air Pollution. Environ. Sci. Technol. 2017, 51, 6957-6964. [CrossRef] [PubMed] 